\title{
La alimentación de la mujer en el embarazo, parto y puerperio en la España de la temprana Edad Moderna*
}

\section{Women's Diet in Pregnancy, Childbirth and Puerperium in Early Modern Spain}

\section{Jesús M. Usunáriz}

https://orcid.org/0000-0001-5274-2397

Universidad de Navarra, GRISO

ESPAÑA

jusunariz@unav.es

[Hipogrifo, (issn: 2328-1308), 9.1, 2021, pp. 673-699]

Recibido: 31-03-2021 / Aceptado: 19-04-2021

DOI: http://dx.doi.org/10.13035/H.2021.09.01.41

Resumen. Los libros de medicina de la España de los siglos XVI y XVII y, especialmente, aquellos dedicados al parto, incluían consejos y sugerencias de alimentación para la mujer durante su preñez, alumbramiento y puerperio. Estas recomendaciones más que seguir los dictados y razonamientos de las tesis humorales y dietética antigua, se basaban en los tradicionales conocimientos, especialmente femeninos, sobre la mejor manera de atender la nutrición de una preñada. Además, procuraban salir al paso de los problemas y complicaciones de cada una de las etapas que vivía una mujer embarazada y parturienta.

Palabras clave. Parto; alimentación y dieta; embarazadas; siglos XVI-XVII; libros de medicina; Siglo de Oro español.

* Este artículo forma parte de los resultados de los proyectos «Universos discursivos e identidad femenina: élites y cultura popular (1600-1850)» financiado por el Ministerio de Economía, Industria y Competitividad (HAR2017-84615-P) y «The Interpretation of Childbirth in Early Modern Spain», subvencionado por FWF Austrian Science Fund (FWF P 32263-G30). Debo agradecer, muy sinceramente, los valiosos consejos y útiles sugerencias aportados por Cristina Tabernero Sala, Wolfram Aichinger y Miren Usunáriz. 
Abstract. The Spanish medical books of 16th and 17th centuries and, especially, those devoted to childbirth, included advice and suggestions for feeding women during their pregnancy, childbirth and puerperium. These recommendations, rather than following the dictates and reasoning of the old humoral and dietary theses, were based on traditional knowledge, especially feminine ones, about the best way to attend to the nutrition of a pregnant woman. In addition, they tried to overcome the problems and complications of each of the stages that a pregnant and parturient woman went through.

Keywords. Childbirth; Feeding; Pregnant women; 16th-17th centuries; Medical books; Spanish Golden Age.

Los trabajos sobre historia de la alimentación se han multiplicado desde los años 90 del siglo pasado en la estela de la Historia de la alimentación dirigida (1996) por Jean-Louis Flandrin y Massimo Montanari. En general, tales estudios se han centrado en los diferentes alimentos utilizados, su producción y el impacto demográfico, la incorporación de nuevos productos (bebidas coloniales, azúcar, chocolate, café), la cantidad de calorías ingerida, las diferencias entre la alimentación campesina y nobiliaria, o las imágenes culinarias en el arte. Además, se han realizado ediciones y estudios de libros y recetarios de cocina de los siglos modernos, entendidos como una de las fuentes principales para el estudio de la gastronomía de la época.

Sin embargo, no debemos olvidar la importancia de la relación entre cocina y medicina, como tuvo a bien resaltar Flandrin?. Así, los libros sobre «regimiento de la salud», además de hablarnos sobre la elaboración de diferentes medicamentos, ponían un especial énfasis en las dietas adecuadas para hacer frente a determinadas enfermedades, situaciones o etapas de la vida. Es en ellos en donde se hace referencia específica a la alimentación femenina, centrada en el embarazo, con una variada gama de consejos dietéticos, y no porque el embarazo se entendiera como enfermedad -era considerado un "estado intermedio o neutro», entre la salud y la enfermedad ${ }^{2}-$ sino por los cambios y trastornos que podía provocar y porque había que lograr, ante todo, su buen desarrollo y fin.

En cualquier caso, este tema, la relación dieta-embarazo, no era nuevo. Tenía una larga tradición preceptiva tanto en los textos ayurvédicos indios como en la cultura grecorromana, y ambas tradiciones confluyeron en la Europa medieval, gracias, en parte, a la introducción de ambas tradiciones por parte de los árabes ${ }^{3}$. Esta es la razón por la cual la relación entre alimentación y embarazo recibió una

1. No obstante, en los últimos años se han publicado trabajos de gran interés como el de Vaughan, 2020. Un breve estado de la cuestión sobre trabajos en torno a las relaciones históricas entre medicina y alimentación en Adelman y Haushofer, 2018.

2. Eshleman, 1974, pp. 24-25.

3. Weiss-Amer, 1993. 
especial atención en la tratadística española de los siglos XVI y XVII al igual que en la europea ${ }^{4}$. Me refiero, sobre todo a los trabajos de Damián Carbón (1541), de Lobera de Ávila (1551); Francisco de Núñez (1580) o Alonso y de los Ruices de Fontecha (1606).

De hecho, si hacemos un repaso a la iconografía del parto durante la temprana Edad Moderna, y me estoy refiriendo con ello a los siglos XVI y XVII, en la mayor parte de las representaciones y escenas («El nacimiento de la Virgen», «El nacimiento de San Juan Bautista» en donde se escenificaba el puerperio de santa Ana y de santa Isabel, etc.) aparecerán una o varias mujeres preparando caldos o llevando alimentos para atender a la mujer en un trance especialmente difícil, pues estaba en juego su vida y la de la criatura ${ }^{5}$.

Pero es más; para cada una de las etapas, entre otras propuestas y remedios, existirán recomendaciones: alimentos favorecedores de la fecundidad, la manera de atender los antojos y las molestas náuseas, las dietas más recomendables durante el embarazo y en las semanas anteriores al parto, opiniones sobre si la embarazada debía seguir o no los ayunos de precepto previstos por la Iglesia, los alimentos que debían dispensarse durante el momento del parto, comidas y productos recomendables para la expulsión de la placenta, o recetas para atender las necesidades de la mujer en su puerperio o postparto, y un largo etcétera.

Pero antes, y como punto de partida, debemos tener en cuenta la vigencia de la tradición hipocrática y galénica, la dietética antigua, y su teoría de los cuatro humores. El ser humano poseía cuatro humores (sangre, flema, bilis negra-melancolía y bilis amarilla-cólera), a los que correspondían unas cualidades (respectivamente, caliente y húmedo, frío y húmedo, frío y seco, caliente y seco). La salud de la persona dependía del equilibrio de estos humores que podía verse alterado por los llamados seis no naturales: el aire o condiciones climáticas, la alimentación (comida y bebida), la actividad y el descanso, el sueño y la vigilia, las excreciones por saciedad o por evacuación, y las emociones y pasiones. En el caso de la dieta, los alimentos, al poseer, por observación empírica, las cualidades de caliente-frío, húmedo-seco, adquirían un valor preventivo para una salud dependiente del equilibrio humoral, según su edad, sexo, ubicación geográfica, etc. ${ }^{6}$ De esta forma, el cuerpo femenino (más frío y húmedo) podía procesar los alimentos (y convertirlos en sustancias vitales) de forma diferente a los hombres ${ }^{7}$. Además, los alimentos poseían otras características que contribuían al equilibrio humoral y podían ser laxativos, diuréticos, sudoríficos o afrodisíacos ${ }^{8}$.

\footnotetext{
4. Como ha recordado, por ejemplo, Gentilcore, 2015, p. 17.

5. Y que recogen una tradición medieval. Sobre la alimentación de la recién parida a partir de fuentes iconográficas españolas ver el trabajo de García Herrero, 2009, o las referencias en González Hernando, 2013. 6. Leschziner, 2006; Keller, 2007, pp. 34-35; Leschziner y Dakin, 2014, p. 201; Gentilcore, 2015, pp. 15-17. 7. Vaughan, 2020, p. 69; Gentilcore, 2015, pp. 17-18.

8. Eshleman, 1974, pp. 4-5.
} 
A partir de estos conceptos, al mismo tiempo básicos y complejos por sus múltiples combinaciones, se establecieron tres tipos de dietas: completa (que contribuía a aumentar la fuerza, apropiada para jóvenes y personas de gran actividad), equilibrada (que ayudaba a conservar la fuerza y la buena salud) y ligera (para los enfermos). En el caso de los enfermos, la dieta se basaba en el siguiente principio: el desequilibrio humoral, que provocaba la enfermedad, podía resolverse con dietas que contuvieran alimentos con características contrarias al humor dominante y provocador de la enfermedad; o con alimentos que contribuyeran a la expulsión y purga del humor ofensivo9.

Otro aspecto a tener en cuenta es el de las teorías que predominaban sobre el valor nutricional de la comida. Según estas, los organismos más próximos o cercanos a la naturaleza al cuerpo humano tendrían un más alto valor nutricional que otros; es decir, los mamíferos más que las aves; estas, más que los peces; estos más que las plantas; etc. A esto se sumaba el principio de las virtudes de lo disímil: por ejemplo, los seres que vivían en el aire (o en lugares altos) eran menos difíciles de digerir, pues el aire les daba cualidades calientes y húmedas ${ }^{10}$, lo cual explicaría, por ejemplo, su presencia continua en todas las etapas del embarazo y puerperio. Además, aquellos alimentos que, en principio, carecían de algunas virtudes, podían completarse gracias al uso de diferentes ingredientes, sobre todo especias, entre las que podía incluirse el azúcar gracias a sus cualidades calientes y húmedas, de ahí su uso reiterado y abundante.

No es extraño, por tanto, que la medicina prestara una especial atención a la alimentación de las embarazadas:

Mucho es menester gran cuidado y mucha ciencia para que las preñadas alimenten bien las criaturas que traen en sus vientres y ellas y las criaturas salgan bien de los partos ${ }^{11}$.

Todo bajo un principio básico: «La vida de la preñada ha de ser previlegiada»12.

\section{ALIMENTOS PARA MEJORAR LA FECUNDIDAD O SUPERAR LA ESTERILIDAD}

El fin del matrimonio era la descendencia, la procreación. Para las familias nobles, pero también para otras, la descendencia del linaje y la posibilidad de transmitir los bienes equivalía a una garantía de continuidad. En este sentido, el embarazo, la maternidad y la paternidad suponían un cambio en el estatus de la mujer y del hombre y un asentamiento de su reputación en el seno de la comunidad ${ }^{13}$. Por eso hubo una preocupación por tratar o atender la esterilidad, tanto en mujeres como

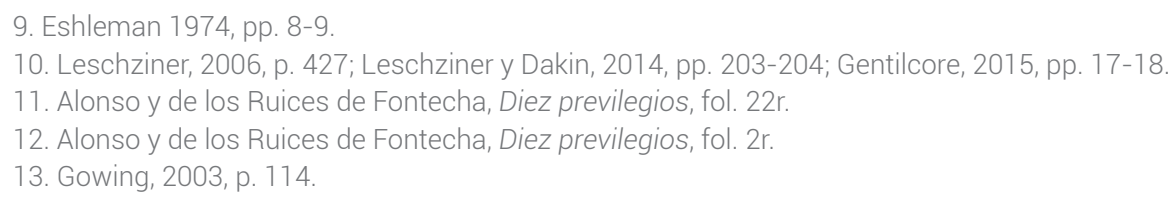


en hombres. Conforme a los criterios de los autores clásicos, como Hipócrates, había incluso métodos para conocer si una mujer podía ser estéril o no. Entre otras pruebas Ruices de Fontecha apunta que si la mujer

ya tomó dos onzas de manteca de vacas y dos de leche de mujer que parió y cría su hijo, y después de habello tomado, regoldó a ello dentro de dos horas, es capaz, si no, no.

$[\ldots]$

O si tomando un ajo fresco, bien mondado y lo pusiere de noche a la boca de la madre y otro día le pareciere que no huele el ajo por la boca, se puede sospechar no concebirá; pero si lo huele, es buena señal, para que puedan pobres y ricas hacer la experiencia ${ }^{14}$.

Hay que tener en cuenta, además, que la matriz se consideraba, tradicionalmente, el corazón del cuerpo femenino; era muy sensible y una mala alimentación (excesivas especias, abundancia de alcohol) podía afectar a la concepción ${ }^{15}$. Por esta razón, estos médicos apuntaban remedios alimenticios, entre otros, para evitar la esterilidad femenina. Lobera de Ávila señalaba:

Ansí mesmo, las mujeres que desean haber hijos hanse de guardar de comer vinagre y cosas agrias, porque alende que secan la simiente y la enfrían, como arriba queda probado, son dañosas a la madre y ansí impiden la preñez ${ }^{16}$.

Además, entre diferentes ungüentos, emplastos, píldoras y jarabes, Lobera sugería:

Use de buen regimiento, como dije, coma cosas callentes, apetitivas y buenas viandas, guárdese de cosas agrias y cosas frías y húmedas, coma frutas verdes y verduras y pescados y de agua fría, como algunas veces asado, y en lo cocido eche cominos, perejil, yerbabuena, orégano; especias aromáticas son buenas. Procure tranquilidad y placer y tenga buena confianza [...]

Otras razones que podían explicar la esterilidad de la mujer hacen referencia a una excesiva delgadez o a la obesidad. En el primer caso, y según los criterios de Hipócrates, la mujer malpariría al segundo mes:

Porque desde aquel tiempo el feto se va augmentando con grandísima brevedad, y para tanto augmento es necesario copioso alimento y es muy dificultoso que una mujer preñada pueda preparar tanta copia de alimento que sea suficiente para su conservación y su augmento y del feto. $Y$ de aquí se sigue que la madre, como más fuerte, toma para sí lo cónmodo y provechoso y se siga el aborto, privado el feto de lo necesario ${ }^{17}$.

14. Alonso y de los Ruices de Fontecha, Diez previlegios, fol. 23v. Siguen otras pruebas.

15. Perkins, 1996, p. 31

16. Lobera de Ávila, Libro del regimiento de la salud, fol. 35r.

17. Álvarez Miraval, Libro intitulado la conservación de la salud, fol. 277v. 
Ahora bien, si la causa de que la mujer no quedase embarazada era su peso excesivo ${ }^{18}$, las recomendaciones eran otras:

Si fuese la causa de no empreñarse la mucha gordura de la madre de todo el cuerpo, dice Rasis y Avicena en los lugares arriba allegados que use de mucho ejercicio, y coma poco y mantenimientos desecativos. No beba vino, y si lo bebiere sea muy poco y tinto, con poco agua [.... ${ }^{19}$.

Por último, si la causa fuere lo que denominan «sequedad de la madre»

hemos de usar de regimiento contrario, haciendo que coma mantenimientos de fácil digestión y de mucha substancia, como yemas de huevos, aves, carnero, cabrito, caldos substanciosos y tortugas y manjar blanco ${ }^{20}$ hecho de las ancas de las ranas. $Y$ beba vino anejo medianamente aguado. Coma el pan bien cernido y limpio de salvado... ${ }^{21}$.

En el caso de que fuera el varón el que tuviese algún impedimento por causa «de la mala complexión de la simiente», entre otros remedios aconsejaba «comer buenas viandas y en moderada cantidad» 22 , pues una buena nutrición era considerada útil para superar el problema de una simiente infértil|23. Por esta razón, si la causa fuera «la flaqueza de los vasos espermáticos», "es singular remedio que acostumbre en los manjares de yerbabuena seca y que tome conserva della por las mañanas», según los dictados de Avicena, porque la yerbabuena «es noble medicina para engrosar la simiente». Además, «use mantenimientos de fácil digestión, guisados con cosas estípticas frías -es decir, astringentes-, si hubiere calor; y con estípticas callentes si hubiere frialdad».

En el caso de que la causa fuera «tener poca simiente», «será útil usar de mantenimientos que críen mucha sangre y aumenten la simiente, como aves, yemas de huevos, piñones y buen vino» ${ }^{24}$. E incluso si el varón «no se halla hábil para acto venéreo», es decir, mostraba signos de impotencia, «tenga este regimiento: que cene poco, así como 3 o 4 yemas de huevos blandos y frescos, use dátiles y piñones echados seis horas en agua callente primero» ${ }^{25}$.

18. Esta asociación entre gordura-obesidad y disfunción generativa se repitió en una amplia gama de textos médicos, anatómicos, de partos y otros más populares de principios del siglo XVI hasta mediados del siglo XVIII tal y como ha demostrado Toulalan, 2014 y a los que ya se refirió Eshleman, 1974, pp. 20-21. 19. Lobera de Ávila, Libro del regimiento de la salud, fol. 39r.

20. El manjar blanco se hacía con una pechuga de gallina machacada, leche, harina de arroz y azúcar, entre otros ingredientes, todo cocido.

21. Lobera de Ávila, Libro del regimiento de la salud, fol. 39r.

22. Lobera de Ávila, Libro del regimiento de la salud, fol. 41 r.

23. Ver, al respecto Evans, 2014, p. 320.

24. Lobera de Ávila, Libro del regimiento de la salud, fol. $41 \mathrm{r}$.

25. Lobera de Ávila, Libro del regimiento de la salud, fol. 41 r. 


\section{LA ALIMENTACIÓN DE LA EMBARAZADA: CARACTERÍSTICAS GENERALES}

Una vez confirmado el embarazo, la alimentación tenía un papel crucial, tanto para evitar un aborto o un nacimiento prematuro de fatales consecuencias, como para impedir la muerte de la madre. En efecto,

Una mala alimentación, en especial una deficiencia de proteínas, podía originar una toxemia, dañar el riñón, elevar la presión sanguínea, desencadenando un parto prematuro, o la muerte del feto debido a anomalías de la placenta o a la prematura separación de la placenta de la pared del útero ${ }^{26}$

Lo apuntó en el siglo XVI Francisco Núñez: había que evitar una mala alimentación en las embarazadas, pues en aquellas mal nutridas «todo el alimento que resciben se va en substantia y nutrimento del cuerpo» «y, por ende, ninguna cosa resta para el nutrimiento de la criatura» ${ }^{27}$. Además, una madre mal alimentada era anuncio de un parto dificultoso:

También si la madre padeció mucha sequía o ayuno, o si estuvo mucho tiempo triste o si al principio del preñado saló o trujo algún peso, o comió poco, o se desmayó, o temió o dio muchos gritos... 28.

El embarazo y la lactancia era, y es, un período de notorio aumento de las necesidades energéticas de las mujeres: las $2240 \mathrm{kcal}$. que una mujer entre los 18 y los 30 años necesitaría en su vida normal, pasaría a ser de 85 kcal más en el primer trimestre del embarazo, $285 \mathrm{kcal}$. más en el segundo, $475 \mathrm{kcal}$. en el tercero, y $675 \mathrm{kcal}$ más en los primeros meses de lactancia, lo que debía afectar notablemente a su dieta y nos habla de un claro peligro de desnutrición en los siglos modernos en épocas, tan frecuentes, de escasez y carestía 29 .

Así lo corroboran también lo estudios de epidemiología histórica que afirman y han demostrado a partir de análisis biométricos, que las altas tasas de mortalidad neonatal, o la mortalidad infantil endógena (anomalías congénitas, bajo peso al nacer, etc.) estaban relacionadas en los siglos XVI-XVII con una mala nutrición materna durante el embarazo, causada por un aumento de los precios del trigo ${ }^{30}$. De hecho, hoy sabemos que, en muchos casos, la nutrición de las embarazadas era inadecuada: el alto consumo de carbohidratos al inicio del embarazo y el descenso al final, o la baja ingesta de proteínas animales, afectaba al crecimiento de la placenta y, por tanto, a la supervivencia del feto ${ }^{31}$.

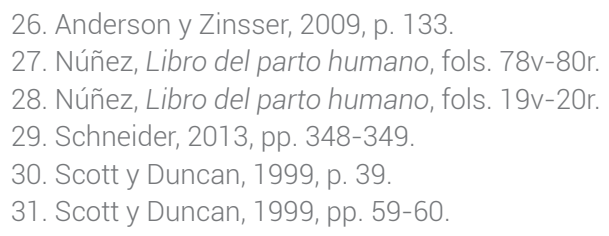


Los tratados médicos resaltaban la importancia de la calidad nutritiva de la sangre de la mujer con la que alimentaba al feto, que dependía, a su vez, de la cantidad y calidad de los alimentos ingeridos 32 . Por eso, los autores pusieron especial cuidado en ofrecer consejos alimenticios para evitar tales problemas, en los que la pauta general era la moderación y la templanza ${ }^{33}$. En el capítulo VIII, «Del regimiento que se debe tener en la mujer preñada», Damián Carbón se centraba, en primer lugar, en el comer y el beber ${ }^{34}$.

Y empezando al comer y beber digo que ha de ser con mucho tiento y mesura, así de la calidad como de la cantidad. El pan ha de ser muy limpio de salvado, porque toda cosa absertiva daña mucho. En tal caso debe abstenerse de toda cosa provocativa de orina o purgativa como hinojo y cosas semejantes. Perdices, pollos, capones y semejantes cosas son provechosas. También tiene de mirar las carnes gordas no ser dañosas, sino con mesura. Y fuere caso que haya la dicha preñada mucha estipidad ${ }^{35}$ de vientre, denle pasas y acelgas. Mas ha de entender que el buen gobierno y regimiento hace buena criatura y buen parto, si por malignidad de la sangre menstrual no es impedido.

El vino que ha de beber ha de ser tinto sotil y viejo, de buen olor. El agua ha de ser con hierro, caliente, acerada. Guardarse ha de cosas ventosas, que procuran aborto.

Después de comer coma cosas de medio sabor es, a saber, entre dulces y agraces $^{36}$.

Lobera de Ávila entre las recomendaciones generales para una mujer preñada, señalaba las siguiente:

Conviene a las mujeres preñadas que se guarden de todas las cosas que dijimos que son causa de aborso, como de ejercicio superfluo, de saltar y de correr y de caídas y de muy gran temor y de muy grande alegría, y de mucho comer y de sufrir hambre, en cuanto pudieren. Y si las preñadas por estar muy flacas se temieren que moverán, conviene que usen de mantenimientos de buena y fácil digestión, y procuren resumirse durmiendo suficientemente y huyendo tristeza y temor ${ }^{37}$.

[...] si se temiere el aborso, porque la mujer preñada ha pasado hambre, ha de enmendarse comiendo poco a poco, y buenos manjares. Y si, por el contrario, hubiere comido o bebido de muy muchos manjares y dellos muy superfluamente, use de muy poco mantenimiento hasta que aquella superfluidad se le acabe ${ }^{38}$.

32. Eshleman, 1974, p. 11

33. Eshleman, 1974, p. 13. Templanza es una de las recomendaciones de Núñez, Libro del parto humano, fol. $89 \mathrm{v}$.

34. Carbón, Libro del arte de las comadres, fol. XIXr.

35. estipidad: es decir, estepticidad, o calidad de estíptico, astringente.

36. Carbón, Libro del arte de las comadres, fol. XIXr.

37. Lobera de Ávila, Libro del regimiento de la salud, fol. 1v.

38. Lobera de Ávila, Libro del regimiento de la salud, fol. 2r. 
Otra recomendación, heredada de Avicena, era que la mujer preñada evitase comer mucha sal, pues la criatura podía nacer sin uñas ${ }^{39}$.

Con anterioridad a todos ellos fue el médico occitano Bernardo Gordonio (c. 1270-1330), en su Lilio de medicina (publicado en latín, en Nápoles en 1480, y en español en 1513), quien dio pautas temporales para la alimentación de la preñada. Así, para evitar que la criatura se moviera, es decir, que se perdiera ${ }^{40}$, en los primeros meses debía evitar la «medicina laxativa» y solo a partir del cuarto mes, podía «limpiar el cuerpo»; si la criatura se moviese «en los postrimeros meses», si la causa fuera el comer, «lo cual se hace por flaqueza, según es dicho, entonces acostumbre dieta resuntiva y gobernadora, y sean todas cosas oledoras». Si esto ocurría a partir del cuarto mes, es decir si la mujer tenía exceso de ventosidades, recomendaba que la mujer hiciera ejercicio fuerte antes de comer y «use de dieta delgada y use cosas fritas y asadas y tostadas» para después usar como diurético un zumo de artemisa, ruda y yerba del huerto cocidas, zumo de acelgas, etc. ${ }^{41}$.

De hecho, durante el embarazo, hasta el último mes, se recomendaban alimentos astringentes, «como son frutas estreñidas y cardos de comer, y como son cosas saladas, queso añejo y vaca y liebre y todo género de caza, así de cuatro pies como de aves, aunque sean perdices. E si las hubieren de comer no sean asadas ni fritas, sino cocidas», a fin de evitar la pérdida de la criatura ${ }^{42}$.

Otros tratados ofrecían consejos alimenticios generales. Así en el libro Sevillana medicina, ofrecía una receta para mujeres preñadas, consistente en «caldo de gaIlina, media libra; huevos, yemas tres; manteca y aceite rosado y alfenique; de cada uno una onza y que sea fecho triste, $\sin$ sal» ${ }^{43}$.

Ahora bien, además de estas recomendaciones generales, los tratados quisieron ofrecer remedios para problemas concretos derivados del embarazo, del cumplimiento de las reglas alimenticias de la Iglesia, o para tratar enfermedades producidas durante el mismo y sin relación con él.

\section{CUIDAdOS DURANTE EL EMBARAZO: LAS NÁUSEAS, LOS ANTOJOS Y LA PICA}

\subsection{Las náuseas}

Al margen de la falta en la menstruación, es decir, la amenorrea, los médicos daban una mayor importancia o seguridad a otros síntomas para determinar, en los

39. López de Corella, Secretos de filosofía, fol. XXXr. Otros autores también aconsejaban un uso moderado de la sal, en cuanto agente teratógeno. Eshleman, 1974, p. 14.

40. Ver sobre el significado de mover como sinónimo de abortar o malparir el artículo de Tabernero, 2020.

41. Gordonio, Lilio de medicina, fol. 189r-189v.

42. Núñez, Libro del parto humano, fol. 25 r.

43. Sevillana medicina, fol. XCIII.

HIPOGRIFO, 9.1, 2021 (pp. 673-699) 
primeros meses, si una mujer estaba embarazada o no ${ }^{44}$. Estos eran las náuseas y el apetito de cosas extraordinarias, y para ambas los médicos daban también sus remedios, en donde la alimentación ocupaba un lugar de primer orden.

Para Plinio, según apuntaba Diego de Yepes, «Diez días después que concibieron [las preñadas] sienten dolores de cabeza, vaguedos, mala gana de comer, fastidio y vómitos. Todo esto es indicio que ha concebido» ${ }^{45}$. En 1603 se daba cuenta del embarazo de la reina Margarita de Austria, esposa de Felipe III, de esta manera:

La jornada que sus Majestades habían de hacer juntos, cesó por haber entrado la Reina en sospecha de preñada a los primeros del mes pasado; lo cual hasta ahora se va de cada día confirmando; y han precedido vómitos y antojos como otras veces que lo ha estado. Dios quiera salga tan cierto como se desea ${ }^{46}$.

Así pues, las náuseas y los antojos eran determinantes. Para Carbón, una de las señales «de la verdadera preñez» era cuando la mujer «tiene ascos y vómitos; está sin apetito de comer» ${ }^{47}$. Ruices de Fontecha, a partir de los estudios de Galeno, y este de Hipócrates, consideraba que se sabía si una mujer estaba embarazada no solo «si le faltó la regla», sino también si «siente gravedad en todo el cuerpo, hastío en el estómago, mala gana de comer, una desigualdad en todo el cuerpo, casi como cuando hay calosfríos, un apetecer cosas fuera de las ordinarias que se comen»48. Y añadía: «si tiene vómitos, si se da de comer carbones, tierras y otras cosas» ${ }^{49}$, por los humores que las preñadas tienen. Y va recogiendo la opinión de diferentes autores (Galeno, Avicena...). Lo mismo apuntaba Lobera de Ávila, que consideraba que una de las señales del embarazo era «que pasado mes y medio o dos meses, les vienen mala gala de comer y gana de vomitar y revolvimiento de estómago y antójanseles cosas que las veces no son para comer, y algunas veces se desmayan ${ }^{50}$.

Para el alivio de estos «vómitos y ascos»

se debe tener grande diligencia en dar las cosas aromáticas y estípticas en todos sus manjares y pónticas -es decir, de sabor áspero o austero- muchas veces,

44. Testimonios sobre la resistencia de los médicos a diagnosticar la existencia de un embarazo solo por la falta de menstruación, ante la posibilidad de que fueran otras causas como la hidropesía, ver Baernstein y Christopoulos, 2014, p. 61. Sin embargo, es obligado destacar la propuesta del médico Alonso Fajardo de León que escribió un tratado en el que afirmaba que «urina hay particular de preñadas», gracias a lo cual podía determinarse la existencia de un embarazo: Apología por la verdad, 1633.

45. Yepes, Discursos de varia historia, fol. 25v.

46. Cabrera de Córdoba, Relación de las cosas sucedidas en la corte de España desde 1599 hasta 1614, p. 224. No es algo baladí: sabemos por ejemplo del agradecimiento de Enrique VIII hacia Lord y Ladie Leile, porque atendieron y satisficieron los antojos de la reina, Jane Seymour, durante su embarazo. Ver Heal, 2008, p. 66

47. Carbón, Libro del arte de las comadres, fol. XVIIIr.

48. Alonso y de los Ruices de Fontecha, Diez previlegios, fol. 26v

49. Alonso y de los Ruices de Fontecha, Diez previlegios, fol. 23v.

50. Lobera de Ávila, Libro del regimiento de la salud, fol. 35r. 
como membrillos cocidos o asados y sinaptizados con polvo de lino, aloes o con galanga, granadas agradulces, confectiones de carne de membrillo o jarabe de membrillo o de agresta ${ }^{51}$.

Pero al margen de esto, había otros métodos que consideraban seguros para determinar la existencia o no de un embarazo. Si una mujer, conforme a la tradición hipocrática, tenía «hastío de la comida» o la «pena» en la «boca del estómago» y tomaba antes de acostarse «dos onzas de miel» o bien «polvos de anís cocidos en un cuartillo de agua dulce», y al levantarse sentía retorcijones, cerca del ombligo, estaba embarazada ${ }^{52}$. Muy similar a lo que también apunta Lobera de Ávila quien recomendaba que la mujer:

cuando se fuere a dormir, tome aguamiel en cantidad de cuatro onzas de cuatro partes de agua llovediza y una cuarta de miel, todo mezclado sin llegarlo al fuego, como dice Galeno en el Comento; y si sintiere en las tripas dolor y contorsión, mayormente en bajo del ombligo, es señal que está preñada ${ }^{53}$.

Y si así fuera: era ¿hijo o hija? «Dice pues Hipócrates en el lugar alegado, toma leche y harina y mézclalo y haz una tortilla y cuécesela en fuego manso, y si se quemara trae hijo, y si se derritiere, trae hija» ${ }^{54}$. Y así otras pruebas, tomadas de Prisciano, que, para Ruices, «parecen tan de risa» ${ }^{55}$.

\subsection{Los antojos y la «pica»}

Hoy se considera que los antojos de una embarazada, entre finales del primer trimestre y con un pico en el segundo, entendidos como un ansia por comer algún tipo de alimento específico, pueden obedecer a diversas causas: para unos son consecuencia de los cambios hormonales y el impacto de estos en el olfato y el gusto; o la necesidad de energía y de nutrientes 56 ; pero también se habla de razones psicológicas: una necesidad de afecto, una mayor demanda de atención por parte de la mujer ante la ansiedad provocada por el embarazo ${ }^{57}$.

Los antojos dieron lugar a comentarios jocosos: «Tiene más antojos que una preñada» recogía Antonio Correa en su Vocabulario de refranes y frases proverbiales (1627). De hecho, no faltaron en la literatura popular, las burlas y sátiras sobre las ansiedades de las parturientas y sus maridos sojuzgados por ellas como aparecen en las Coplas divertidas de Juan Lanas, del hombre que volvió del campo y encontró a su mujer muy cercana al parto ${ }^{58}$.

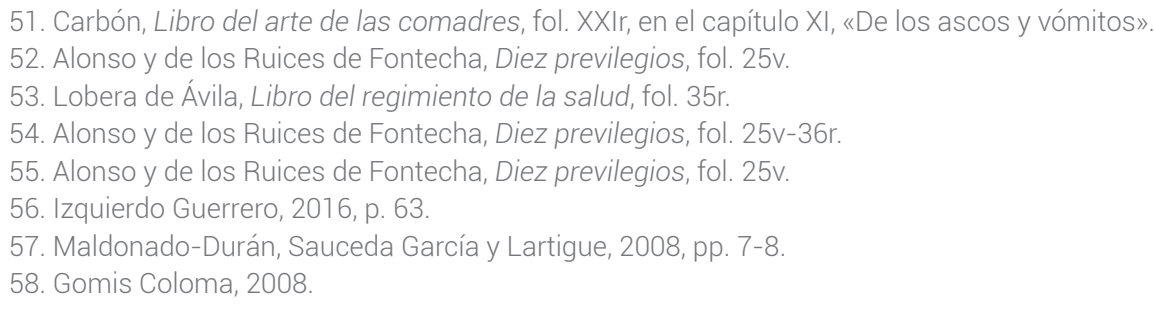


Pero, en cualquier caso, para otros muchos, los antojos obedecían a un incremento de la actividad imaginativa de las mujeres embarazadas y la especial relación simbiótica entre la criatura y la madre:

No hay preñado que no traiga sus antojos [...] Los antojos más se atribuyen a la criatura que anda en el vientre que no a la madre. Que por secreto misterio de la naturaleza, estando la criatura dentro de las entrañas de la madre le da antojo y gana de una cosa y le comunica a la madre tanto deseo della, que a veces viene a morir si no le cumple su antojo ${ }^{59}$.

La «hipótesis imaginacionista» o la «teoría de la impresión materna», tuvo un amplio consenso científico y popular. Según esta, la imaginación de la madre podría tener una influencia en el desarrollo del feto al quedar impresionadas en él las ensoñaciones o deseos de la progenitora ${ }^{60}$. Se fundamentaba en dos ideas: la primera, que la mujer embarazada debía evitar experiencias perturbadoras, pues esto podía quedar impreso en una deformidad física de la criatura; la segunda que, si no se atendían las apetencias, especialmente alimenticias, de la embarazada, se temía que el nasciturus pudiera quedar marcado de por vida por una señal en su piel, o incluso morirse si la madre no comía aquello que deseaba ${ }^{61}$. De Carlos Varona recoge el testimonio de cómo un cuadro de José de Ribera, Ixión, para el comerciante de Ámsterdam Lucas van Uffel, fue rechazado y devuelto a Italia después de que su esposa, embarazada, tras contemplarlo, diera a luz un niño con un dedo «malformado y torcido», pues la figura de Ixión tenía una mano deformada62. Así, a un incumplimiento de los antojos se debían los «lunares»: estos se definían en el Diccionario de autoridades como «la mancha o señal que, en el rostro o otra parte del cuerpo, suelen sacar del vientre de su madre algunas criaturas, de los cuales unos son mayores que otros, de color pardo o negro, y algunas veces rojo» (Aut., s. v. lunar). El padre Nieremberg mencionó los efectos de la imaginación: «como son las cerezas, fresas y otras frutas con que han nacido las criaturas figuradas en las partes del cuerpo, por antojo infeliz de las madres» ${ }^{63}$. No extraña, por tanto,

59. De la Vega, Paraíso de la gloria. Ver al respecto los interesantes testimonios de Kremmel, 2018, pp. 468-470.

60. Ver al respecto los trabajos de López Gutiérrez, 2012, p. 30 y González Rovira, 1997, pp. 22-23. Pedro Mejía, en su Silva, en 1545, insistía en la fuerza de la imaginación: «La vehemente y recia imaginación puede mover las especies con tanta fuerza que imprima y pinte en ellas la figura de la cosa imaginada, y ellas la obre en la sangre. Es esto de tanta fuerza que aun en los miembros y persona ajena se puede hacer, como vemos de la mujer preñada, que con la fuerte imaginación de lo que se le antoja, imprime muchas señales en la criatura y a veces la mata» (Mejía, Silva de varia leción, fol. LVv)

61. Roodenburg, 1988, p. 701; Epstein, 1995, p. 148; Rublack, 1996, pp. 93-94; López Gutiérrez, 2012, p. 29.

62. De Carlos Varona, 2018, pp. 123-124.

63. Nieremberg, Curiosa filosofía, fol. 54r. «También se han visto notables efectos originados de antojos, que por fuerza de la imaginación se ha visto salir la criatura marcada con aquello que se le antojó a la madre y no pudo conseguir. A la abuela de Nieremberg se le antojaron unas fresas y triste por no poder conseguirlas puso la mano en la cabeza rascándola, que es ación natural en semejantes lances y la criatura nació con cinco bultos en la cabeza en aquella parte en que la madre asentó los dedos, los cuales bultos eran del tamaño y color de fresas, y cortándoselos cada año volvían de nuevo a nacer, lo cual se continuó por espacio de diez años» (Fuenlapeña, Discurso único, p. 56).. 
la repercusión pública que tenían los llamados «partos monstruosos» que aparecen en diversa literatura y especialmente en las relaciones de sucesos. De hecho, un parto monstruoso podía tener mucha relación con el incumplimiento de estos antojos y deseos ${ }^{64}$.

Todo esto, lejos de responder a una creencia irracional, incluso neurótica, era el resultado de una construcción y concepción cultural que tenía la función de contribuir a la estabilidad emocional de la embarazada ${ }^{65}$. Pero no solo cultural: las náuseas, los antojos, los vómitos, las fatigas de las embarazadas no eran «embelecos, damerías ni melindres», "sino obras tan puramente de naturaleza y de sus principios» ${ }^{66}$.

Por eso, en un momento en el que la inseguridad y el miedo, pero también la esperanza, en definitiva, un sentimiento de ambivalencia, rodeaba la vida de la mujer, los hombres, futuros padres, tenían la obligación de cumplir con sus deseos y peticiones, a fin de evitar un mal parto o las deformaciones de un feto estrechamente vinculado a su madre ${ }^{67}$.

Esta ansiedad alimenticia podía convertirse en un desorden peligroso. Era la «pica», «pica famis» 0 «apetitos de cosas extraordinarias» ${ }^{68}$. Así, «fuera de orden», solían comer «tierra, carbón y otras cosas», «ceniza, carbones, brasas vivas» e incluso apetecían de carne humana ${ }^{69}$. Sorapán de Rieros, en su comentario al refrán III «De hambre a nadie vi morir, de mucho comer cien mil», viene a distinguir diferentes tipos de hambre, una de las cuales,

que no es natural se dice en griego malakias y en latín pica, Ilamada así, según algunos dicen, por la ave que en castellano decimos urraca. Este género de hambre, no solo se apetece mucha comida, pero apétecese y contraria. Suele afligir a las preñadas esta afección y hay algunas que, si no cumplen luego su antojo, lanzan de sí la criatura. Yo he visto alguna que dio en comer naranjas agrias y dejándose llevar de su gusto despachó en un día docientas; otras he visto comer tanto queso que parece cosa increíble ${ }^{70}$.

Esta enfermedad se originaba, conforme a la tradición galénica, porque las embarazadas no purgaban sangre ${ }^{71}$.

64. Rublack, 1996, pp. 94-96

65. Roodenburg, 1988, pp. 711-712

66. Alonso y de los Ruices de Fontecha, Diez previlegios, fol. 1r-1v.

67. Usunáriz, 2018.

68. Alonso y de los Ruices de Fontecha, Diez previlegios, fol. 22v; Barrios, Verdadera medicina, fol. 98r-98v. 69. Alonso y de los Ruices de Fontecha 1606, fols. 27v-28r; Bovistuau, El Teatro del Mundo, fol. 35r. Sobre la pica Eshleman, 1974, pp. 25-27 y Albala, 2002, p. 69

70. Sorapán de Rieros, Medicina española, p. 27.

71. Alonso y de los Ruices de Fontecha, Diez previlegios, fols. 27v-28r y 64r-64v; López de Corella, Secretos de filosofía, fol. XLVIIIV. 
Tanto para los antojos como para la malsana pica había algunos remedios alimenticios: las manzanas «de Media o de Persia, llamadas cedromela, que se dicen en latín citria», «muy útil en los graves hastíos de las preñadas y en aquella suerte de antojo que llaman citta los griegos» ${ }^{72}$. O los de Gordonio:

E si la mujer preñada cobdiciare cosas malas sea dietada con cosas asadas y fritas y fritas y oledoras. Y después del comer coma peras y membrillos, granadas, avellanas tostadas, castañas y garbanzos tostados ${ }^{73}$.

\section{3. ¿Debía la embarazada respetar los días de ayuno establecidos?}

Ahora bien, si queremos hablar de alimentación no podemos olvidarnos de tratar sobre los ayunos establecidos por la Iglesia y su repercusión, en nuestro caso, sobre las mujeres embarazadas. Entre otras razones porque no debemos olvidar del significado religioso de la alimentación y la estrecha vinculación entre la comida y el comportamiento cristiano; no en vano el ayuno es uno de los cinco mandamientos de la Iglesia católica ${ }^{74}$. Dentro de los cuatro tipos de ayuno (espiritual, natural, moral y eclesiástico) ${ }^{75}$, es este último el que nos incumbe ${ }^{76}$. El ayuno eclesiástico, a su vez, se dividía en tres: el ayuno de ley, que consistía en la abstinencia de carne y lacticinios (es decir leches y sus derivados y huevos); el ayuno de privilegio, que suponía abstinencia de carne, pero no de lacticinios; y el ayuno de dispensación, que consistía en una sola comida al día (al mediodía) pero sin abstinencia de carne, huevos y lacticinios. El ayuno de privilegio afectaba: a los cuarenta días de Cuaresma, salvo los domingos; a las cuatro témporas del año (miércoles, viernes y sábado), en los cuales se podían tomar lacticinios; los miércoles, viernes y sábados de cada semana, aunque los sábados, al menos en Castilla, se permitía comer las extremidades de las reses, desde 1212 (en estos el ayuno era semipleno, solo abstinencia de carne, de ahí que se denominen «días de pescado»; rogaciones y letanías: la semana antes de la Ascensión, lunes y martes, eran días de pescado, pero no de ayuno; el ayuno de «estaciones y vigilias», es decir, «la víspera de alguna grande solemnidad»: Navidad, Asunción de Nuestra Señora, Apóstoles (salvo San Felipe, Santiago y San Juan), Pentecostés, San Juan Bautista, San Lorenzo, y Todos los Santos, y otras solemnidades dependiendo de las diócesis (el patrón de alguna ciudad). Y «si alguna vigilia cayere en domingo» debía ayunarse «el sábado antecedente» ${ }^{77}$.

72. Dioscórides Anazarbeo, Acerca de la materia medicinal, p. 102.

73. Gordonio, Lilio de medicina, fol. 189v. Para evitar los «malos apetitos» que solían tener las preñadas, era útil «un poco de polvo o harina de habas a solas o mezclada con miel, o unos huevos con cominos, pueden comer de algún membrillo, pera o granada agria dulce, preparando y corrigiendo lo que tienen ventoso, que eso es razón se evite en las preñadas». También era bueno «que coman asado y beban vinos» (Alonso y de los Ruices de Fontecha, Diez previlegios, fol. 74r).

74. Al respecto son de gran interés los trabajos de Bynum, 1985 y 1988.

75. Sierra, Mapa de arcanos, pp. 336-337.

76. Un buen resumen de sus características en el trabajo de Ferlan, 2018.

77. Sierra, Mapa de arcanos, p. 364. 
Aunque, en un principio, se dio cierto debate entre algunos canonistas que consideraban que las preñadas sanas y robustas no debían quedar exentas del ayuno ${ }^{78}$, muy pronto la respuesta fue unánime. En el capítulo XIII, «Del ayuno de la Iglesia», de la Parte Cuarta del Hábito y armadura espiritual de Diego Cabranes se dice:

Las mujeres preñadas son libertadas de precepto porque si es al principio de su preñez puede haber peligro de mover la criatura, porque en aquel tiempo hay muy grandes alteraciones en su cuerpo, y si hobiese alguna falta de esfuerzo habría peligro. Ansí mismo, cuando la criatura está ya de días, ha menester alimento, porque son dos personas y han menester rescebir alimento de comer para dos y de su sustancia de la madre por ciertas venas y caminos se provee la criatura en el vientre donde está.

Ítem puede ser la flaqueza de la madre débil y conviene comer a menudo para el alimento de los dos.

La misma causa damos para las que crían, que son excusadas del ayuno por la falta que habrá de la leche para la criatura ${ }^{79}$.

Por esta razón Ruices se centra en hablar de la necesidad del alimento para las embarazadas:

Viniendo pues al propósito. Si los inconvenientes dichos que se siguen al estómago vacío serán de mayor consideración en las preñadas y en las utilidades y comodidades de más provecho, pues podrá evitar un aborso, aunque tengan sangre, que es bastante alimento inmediato para la madre y la criatura. Será menester dalles a comer tan a menudo que aquello no falte en el estómago. Lo cual, como no se puede mensurar con tiempo, no se les puede obligar a que estén sin comer el tiempo que pide el ayuno ${ }^{80}$.

A comienzos del siglo XVIII, Martín de la Sierra seguía las mismas pautas: las mujeres preñadas y las que crían debían estar exentas

aunque tengan robusta salud, porque necesitan de continuo alimento. Y haciendo lo contrario se exponen a peligro de aborto la una, y la otra de que se inficione lo que ha de servir de alimento al niño. Este privilegio, oyentes míos, sirve solo para no ayunar, no para comer de carne, pues gozando buena salud pueden así, unas como otras, comer manjares de viernes, salvo si las preñadas tuviesen apetito vehemente, que el vulgo llama antojo, a manjar de carne, y la que cría tuviese el chiquillo enfermo. Y para quitar escrúpulos, habiendo oportunidad, consultar con el médico y con el confesor ${ }^{87}$.

78. Sánchez, Triángulo de las tres virtudes, fol. 225v.

79. Cabranes, Hábito y armadura, fol. 51r. También en León Libro Ilamado guía del cielo, fol. CXXXIIIV, Espejo de la consciencia, fol. CLXXXIIr o Alonso de los Ruices y de Fontecha, Diez previlegios, fol. 54r. En la carta de Francisco de Sales a una señora casada que estaba embarazada (Epístola LXXXIII) le aconsejaba: «Pero, ¿qué es esto que me dicen? ¿Qué estando preñada ayunáis y defraudáis vuestro fruto del alimento que se requiere a la madre para darle el que le es debido? No lo hagáis más, os suplico, y humillándoos debajo del parecer de los doctores, alimentad vuestro cuerpo sin escrúpulo, en consideración del que traéis en vuestro vientre» (Sales, Cartas espirituales, p. 300).

80. Alonso y de los Ruices de Fontecha, Diez previlegios, fol. 64r-64v.

81. Sierra, Mapa de arcanos, pp. 356-357. 
Así pues, la mujer embarazada, en cuanto que dispensadora de comida y como tal responsable de la vida de la criatura, debía evitar cualquier cosa que pudiera derivar en daño para el feto. Quedaba, por tanto, exenta, del ayuno.

\subsection{Otros cuidados}

Además de estos inconvenientes, los tratados quisieron abordar otros problemas. Así, en caso de enfermedad, ¿era recomendable o prudente que una embarazada se sometiera a una sangría? La sangría, o «incisión de la vena para que se evacúe la sangre» (Aut.) era un remedio médico, eficaz para sacar «los humores corrompidos» que no podía negarse a la embarazada en caso de enfermedad, a pesar de los criterios de aquellos (como Hipócrates y Galeno) que consideraban que había que conservar la sangre de la madre pues a través de ella se alimentaba la criatura y porque consideraban que la sangría podría provocar un aborto. De ahí que Ruices de Fontecha no lo descartase, aunque sí recomendaba cautela y moderación en su uso, y considerase uno de los privilegios de las preñadas el poder someterse a este tratamiento. Pero para ello, antes del sangrado, daba algunos consejos alimenticios y recomendaba que se diera a la mujer «su pedazo de carne, no muy asada, con sus polvos aromáticos y corroborantes» o bien, una hora antes, «un huevo blando o cuatro tragos de buena sustancia, con un escrúpulo de coral blanco y colorado», se podía sangrar a las mujeres sin peligro ${ }^{82}$.

Por último, los autores esmeraban sus consejos alimenticios un mes antes del parto para salir al paso de diferentes problemas y, sobre todo, para facilitar el mismo. Así, para evitar úlceras o similares que «cierran los senos de la matriz», entre otras cosas debe «usar alimentos blandos y no agrios y que resquemen» 83 .

Si estuviese estreñida,

debe el mes antes del parto usar de medicinas que ablanden y desaten el vientre, conviene a saber, de manzanas asadas, de mañana, en ayunas, y bebiendo tras ellas unos tragos de vino puro, y comiendo mañana y tarde unos higos pasados. Debe guardarse en el ínterin de cosas que estriñen y aprieta, como son cosas tostadas y fritas, allende desto guárdense de arroz, de huevos duros, de mijo y sus semejantes, y si fuere necesario usar de clisteres blandos de caldos de pollos o pollas, y alguna vez tomar por la boca alguna cosa que ablande y mollifique el vientre, conviene a saber, aceite de almendras dulces en poca cantidad, azúcar de rocas pérsicas, caldo de mercuriales, un poco de suero con azúcar ${ }^{84}$.

Si se hallara débil:

Empero si la preñada, allegándose ya el parto estuviere débil y flaca, débese reforzar con mantenimientos y bebidas y con lectuarios conortosos. Finalmente se aparejen aquellas cosas las cuales puedan preparar y habilitar la preñada para 
el parto, cuales son todas aquellas cosas que relajan y mollifican y ablandan la natura, conviene a saber, que ensanchen y amplíen y faciliten el orificio de la matriz, para la salida de la criatura. Esto especialmente se debe hacer en las primerizas y jóvenes, porque como dijimos arriba por autoridad de Hipócrates, estas más trabarían en el parto; pues mujeres que son de mayor edad tienen orificios mayores, aunque más duros y secos. Y por ende han de ser de cosas calientes y húmidas para que humedezcan y ablanden la matriz, ansí tomándolas por la boca como untando por de fuera por la boca caldos gruesos de capones o gallinas [...].

Debe en el ínterin la preñada usar de vino muy bueno añejo, que no sea acedo en manera alguna, bien aguado ${ }^{85}$.

Lobera de Ávila animaba a evitar, en los últimos meses de preñez, los «manjares que aprietan y desecan» o «cosas estíticas», como lentejas, castañas, peras, etc. Y sugería ciruelas pasas cocidas, higos, granadas dulces y evitar los asados. También tenía beneficios iniciar la comida con una escudilla de caldo de ave o de carnero «con media onza de azúcar», con alimentos que facilitasen la digestión, y vinos suaves o aguados ${ }^{86}$.

Entre los consejos de Ruices de Fontecha para facilitar el parto, recomendaba «la laxidad del vaso y partes circunvecinas», para lo que recomendaba «los fomentos, de cocimiento, de flor de manzanilla, de malvas, malvaviscos, violetas, simiente de lino, alholvas, pepitas de membrillos, enjundias, aceites de azucenas de almendras dulces, mucilagines, bebidas de leche humano y otras cosas semejantes que humedecen los lugares dichos y calienten con moderación» ${ }^{87}$.

Poco antes del parto, unos diez días antes, además de baños aromáticos y ungüentos en la matriz, ofrecían sus propias pautas alimenticias

que la preñada use de un buen regimiento, conviene a saber de alimentos confortativos y de los mejores que se puedan haber, de vinos muy suaves y gustosos. Fuera desto debe hacer algún ejercicio o obrando de manos o meneándose y andando y estando de pie algo más de lo que acostumbró 88 .

\section{EL PARTO Y MEDIOS PARA AYUDAR AL PARTO}

Cuando comenzaban los dolores de parto «y los humores que hasta entonces están recogidos en las pares empiezan ya a salir afuera, que es lo que vulgarmente se dice, romperse la fuente», el papel de la comadre era fundamental. Para unos, como Núñez, esta debía confortar y recrear a la parturienta «con alimentos y conservas y bebidas» ${ }^{89}$. Bernardo Gordonio recomendaba que la parturienta comiese,

85. Núñez, Libro del parto humano, fol. 24r-24v.

86. Lobera de Ávila, Libro del regimiento, fols. 60v-63v.

87. Alonso y de los Ruices de Fontecha, Diez previlegios, fol. 99r-99v

88. Núñez, Libro del parto humano, fol. 27r.

89. Núñez, Libro del parto humano, fols. 29v-30r. 
en poca cantidad, «caldo de gallina gorda, y beba vino oledor» ${ }^{90}$. Lobera de Ávila recomendaba a la partera que, «con buen ánimo y alegre cara», diese esperanza a la mujer de que todo iba a ir bien y sin peligro, y que le diese

conservas o camuesas o yemas de huevos o unos tragos de vino blanco añejo de Pelayos, si se podiere haber, o si no de Sant Martín o de otras partes que sea bueno oloroso, porque en este tiempo no ha de comer cosas de recia degistión ni en mucha cantidad como Avicena lo manda, aunque al revés lo hacen nuestros tiempos las mujeres ${ }^{91}$.

Otros, como Ruices de Fontecha, eran partidarios de que las comadres no les diesen nada de comer, pues la comida no daba lugar sino a «muchos trabajos». En la línea del médico griego Moschión, recomendaba «que la que pare esté en ayunas», «porque si el estómago está lleno de comida, más trabaja el útero cuando se distiende, también trabaja más la mujer agravada con el mantenimiento, de manera que ante todas cosas se han de guardar mucho estas dos: que entonces no se le dé de comer y esté queda y no ande, y lleve los dolores sin fatigarse» ${ }^{92}$.

Pero en el caso de que hubiera que dispensar comida, Ruices y el resto de autores perseguían tres objetivos: dar fuerzas a una parturienta débil93; facilitar la salida de la criatura; y contribuir a la expulsión de la placenta ${ }^{94}$.

Para una parturienta que experimentara alguna debilidad, Ruices de Fontecha, conforme a los consejos de Avicena y de otros autores, daba recomendaciones a las comadres. Así pues,

se le ha de dar a la preñada que estuviere débil y flaca, antes de asentalla en la silla o de ponella en el lugar donde ha de parir, algún poco de buen caldo o otro buen mantenimiento, en poca cantidad, como son yemas de huevos bebidas o otros mantenimientos tan fáciles como estos. Su comentador, lacobo, dice serán buenos turmillas de pollos o algún poco de pechuga de perdiz, pollo o faisán y que le den tragos de buen vino, en hasta dos o tres onzas. [...] Su comentador [se refiere de nuevo a Jacobo] parece que pasaba bien adelante con el privilegio y quiere que le den a la que quiere ya parir abundantemente caldo, si la virtud está débil, y que sea de capón, gallina o pollo [...] $]^{95}$.

90. Gordonio, Lilio de medicina, fol. 190r.

91. Lobera de Ávila, Libro del regimiento, fol. 65r.

92. Alonso y de los Ruices de Fontecha, Diez previlegios, fol. 125r.

93. Como apunta Aichinger, este aspecto, el de dar fuerzas a la parturienta, señala la diferencia entre el Siglo de Oro, cuando la mujer pare por sus propias fuerzas, y nuestra contemporaneidad, donde los remedios médicos cobran un mayor protagonismo (Aichinger, 2018, pp. 409-410).

94. En los casos más trágicos también se daban remedios para la expulsión de la criatura muerta, pero solían ser brebajes y zumos de yerbas. Por ejemplo, en Núñez, Libro del parto, fols. 95v y 97r; Alonso y de los Ruices de Fontecha, Diez previlegios, fols. 150r y ss.; o en el manuscrito Recetas experimentadas para diversas cosas, fol. 239r (BNE, Ms. 2019).

95. Alonso y de los Ruices de Fontecha, Diez previlegios, fols. 123v-124r y $126 \mathrm{~V}$. 
A fin de contribuir a una expulsión si no rápida, sí menos dificultosa, de la criatura, todos se mostraban partidarios de que se evitase dar a la mujer en el parto alimentos astringentes. Conforme a Jerónimo Mercurial, se recomendaba

no les den en aquella hora mantenimientos astringentes (como membrillos, aceitunas, peras verdes y otros desde jaez); les permite carnes pingues, como de capones y gallinas gordas, de carneros capados y aceite. De parecer de Hipócrates, libro De morbos murieron, manteca, pasas, higos pasos, malvas y acelgas, y todos los mantenimientos que tienen virtud de ablandar, como no la tengan de abrir, porque los tales podrían ser de inconveniente, ayudando a que se abriese el vaso y caminos antes de tiempos ${ }^{96}$

Francisco Núñez sugería administrar a la mujer «caldo de garbanzos» o «vino aguado» mezclado con una pequeña porción de asafétida o canela, pues «hará salir la criatura» ${ }^{97}$. Otros recomendaban una mezcla de polvos de cuescos de dátiles, azafrán, canela y clavo con vino blanco, siendo especialmente repetida la mezcla de vino y canela ${ }^{98}$. Y Ruices, en su defensa particular del ayuno de la parturienta, frente a la práctica habitual de dar caldos a las parturientas, «que puedan dalles congoja en el estómago», apuntaba una especie de «terapia de olores» (de pan reciente, de tocino, de buenos caldos, de vino tibio), como sustitutivo ${ }^{99}$.

Uno de los momentos capitales del momento del parto era la acertada y completa expulsión de la placenta. Si esto no se llevaba a cabo «por flaqueza de la parida» había que proporcionarle las fuerzas necesarias, «a saber, con algún potaje gordo y hiemas de huevos, con vino añejo, con algunas carnes gordas de gallinas, faisanes, perdices, capones, tórtolas y otras carnes semejantes» ${ }^{100}$. En el caso de que no salieran había que aplicar otros remedios «que provoquen y llamen las pares y que las hagan humedad y correntías» y que también «ensanchen y relajen la matriz». Para ello Núñez recomendaba diversos polvos y yerbas, mezcladas con «zumo de berzas y de puerros» ${ }^{101}$.

96. Alonso y de los Ruices de Fontecha, Diez previlegios, fols. 123v-124r.

97. Núñez, Libro del parto humano, fols. 42r-43r. También llega a decir que dar de comer «carne de lobo» aceleraba el parto, fol. 45v. Lobera de Ávila también era partidario mezclar asafétida con un caldo de garbanzos negros, Lobera de Ávila, Libro del regimiento, fol. 52v. Ruices animaba a que las mujeres comiesen carnes asadas «porque mascándolas se hace fuerza y se ayuda al parto, Alonso y de los Ruices de Fontecha, Diez previlegios, fol. 124v.

98. Ruscelli, Secretos del reverendo don Alexo Piamontés, fol. 182r-182v; «Recetas experimentadas para diversas cosas», BNE, Ms. 2019, fols. 229v-230r. Esta y otras recetas similares para facilitar la expulsión de la criatura, viva o muerta, procede del famoso Libro de medicina llamado tesoro de pobres con un regimiento de sanidad, de Arnado de Vilanova en cuyos capítulos XLIV y XLV presta atención a las parturientas: «Para la mujer que ha fuerte parto» y de su remedio; $y$ «Para las mujeres que no quedan purgadas y de su remedio» (Barcelona, Bernat Cuçana, 1596), que recoge parte de sus escritos de fínales del siglo XIII y primera década del siglo XIV.

99. Alonso y de los Ruices de Fontecha, Diez previlegios, fol. 126v.

100. Núñez, Libro del parto humano, fol. 48r

101. Núñez, Libro del parto humano, fol. 53r-53v. Lobera había hecho con anterioridad las mismas sugerencias: «será útil confortar la virtud dando a comer a la parida mantenimientos muy sustanciosos fáciles de degistión, como caldo de aves gruesas, yemas de huevos, vino añejo aguado, lo que baste, 


\section{TRAS EL PARTO}

Tras el parto lo que se va aplicar es, fundamentalmente, una cocina de convalecencia, es decir, aquellas técnicas culinarias y platos preparados que se consideran apropiadas para personas débiles que se están recuperando de una enfermedad ${ }^{102}$. En el caso de las parturientas se hace mención, especialmente, de alimentos que se creía contribuían a la «purgación» o la expulsión de los malos humores tras el alumbramiento; los que aliviaran los dolores de útero; los que procuraban salir al paso de algunas complicaciones comunes tras el parto; y los que facilitaran la recuperación física de la mujer. A esto había que sumar otro factor determinante: un régimen alimenticio para que la madre pudiese amamantar, en las mejores condiciones, a la nueva criatura.

Entre los elementos que ayudan a la purgación de la parida, entre otros remedios, de nuevo se acudía a «cocimientos» de garbanzos, «caldo de gallinas y chupar el zumo de granadas dulces porque mueve la purgación y tiempla la calentura». También era bueno el «zumo del puerro con vino blanco, y si comiere pulpo, y si bebiere la simiente del espárrago y del apio con vino blanco» ${ }^{103}$, entre otros brebajes. Por su parte, para la purgación, Juan de la Torre y Valcárcel recomendaba:

En pasando el tercer día del parto, siempre una taza de caldo y una onza de aceite de almendras dulces y otra de azúcar. Y deben también los primeros seis días comer asado, beber agua cocida de culantrillo todo el tiempo de la purgación, que siempre se debe solicitar ${ }^{104}$.

Los autores contaban también con otros problemas: para la fiebre o calentura tras el parto se recomendaban "granadas dulces y agua de cebada» 105 . Si la parida sufría de hinchazón, cocimiento de garbanzos, o polvos de garbanzos y cominos mezclados con vino añejo ${ }^{106}$. Un vino que también estaba omnipresente como remedio de los dolores posteriores al parto, los «tuertos» y la «matriz salida» ${ }^{107}$, pero

pollas, capones y perdigones nuevos» Lobera de Ávila, Libro del regimiento, fol. 67r. Y lo mismo hará Alonso y de los Ruices de Fontecha, Diez previlegios, fol. 146r: «con buenos caldos, pero muy gordos, para que juntamente ayuden a reparar fuerzas y ablandar y así se harán luego, conforme la posibilidad de la parida, de aves preciadas gordas o de carnes, echando las enjundias a cocer». Este también sugería dar a la parturienta, siguiendo a Hipócrates, «una miga de pan mojada en buen caldo, huevos bebidos, carnes de aves y principalmente buenos caldos». El vino sea oloroso y si la mujer se desmayare, como acontece muchas veces y muy de ordinario, dice la socorran con olores» (Alonso y de los Ruices de Fontecha, Diez previlegios, fol. 124v). En la misma línea Soriano hablaba «de zumo de borrajas, de zumo de puerros y de zumo de perejil» bebido con vino o aceite de almendras dulces (Soriano, Libro de experimentos médicos, fol. 78v)

102. Albala, 2012, p. 323.

103. Núñez, Libro del parto humano, fol. 59r-59v.

104. Torre y Valcárcel, Espejo de la filosofía, fol. 154v.

105. Lobera de Ávila, Libro del regimiento, fol. 72r-72v.

106. Núñez, Libro del parto humano, fol. 60r-60v; Lobera de Ávila, Libro del regimiento, fol. $72 v$.

107. Núñez, Libro del parto humano, fol. 64r. 
también «una taza de agua de flor de manzanilla, digo de cocimiento, porque es admirable remedio, y a las más melindrosas se les puede dar seis onzas de agua de azahar» 108

Pero, quizás, el más tajante en los consejos alimenticios para la mujer en el puerperio, fue Lobera de Ávila, que seguía a Avicena:

conviene que las paridas no coman mucho manjar luego como han parido, porque les hará venir calentura. Yo creo que por no guardar este consejo de Avicena han muchas mujeres paridas caído en enfermedades incurables, porque a la hora en pariendo no hacen otra cosa las parteras y otras mujeres sino hartarlas de carne y pan y vino puro y rebanadas con manteca, y huevos y miel. Y como ellas están muy debilitadas de los dolores y la purgación del parto no tienen virtud suficiente para digerir tanto manjar, y así corrómpeseles el estómago y en el hígado y es causa de venir calentura y otras enfermedades, por lo cual deben las tales usar buenas viandas y en poca cantidad como pollas, gallinas y capones y otras semejantes. Porque según testifica Galieno, no se substenta nuestro cuerpo de lo que comemos sino de lo que digerimos ${ }^{109}$.

En líneas generales y para la recuperación física de la parturienta, todos los autores recomendaban una alimentación basada en la ingesta de huevos, caldos, carnes de ave, o frutas, como granada dulce, almendras dulces, azúcar110.

Un tipo de alimentación casi intuitiva, ajena a las tesis humorales de la época, que se repite a lo largo de los siglos y que obedece a lo que es el conocimiento tradicional de qué alimentos son necesarios para un convaleciente. Esos poseían cuatro características: eran nutritivos, reconstituyentes, fáciles de digerir y ligeros $^{111}$. Según Ruices de Fontecha: «será bien dar de comer algo bueno y fácil de gastar por los dos días primeros y así ir procediendo con buen orden, hasta que se hayan acabado las purgaciones del parto, porque ya se puede tratar la preñada como sana» ${ }^{112}$.

La alimentación del niño recién nacido debía ser, necesariamente, la leche, bien de la propia madre, bien de lo que algunos autores, de manera desacertada han denominado «lactancia mercenaria», es decir, una nodriza o ama de cría. Afirma Lobera (como Núñez),

según escribe Avicena y es común sentencia de todos los doctores, la leche más conviniente al niño es la de su madre y por todas las vías que fuere posible se ha de procurar que su madre le dé leche, porque es el mesmo mantenimiento que el niño tenía antes que naciese, y por tanto le es más saludable y semejante que otra leche ${ }^{113}$.

108. Alonso y de los Ruices de Fontecha, Diez previlegios, fol. 158v.

109. Lobera de Ávila, Libro del regimiento, fol. 72r-72v.

110. De Carlos Varona, 2018, p. 107. Ver, por ejemplo, además de los citados, Torre y Valcárcel, Espejo de filolosofía, fol. 154r-154v.

111. Albala, 2012, p. 324.

112. Alonso y de los Ruices de Fontecha, Diez previlegios, fol. 156r

113. Lobera de Ávila, Libro del regimiento, fol. 76 r (cap. Xv). 
No obstante, la elección nodriza, como señala Ruices de Fontecha, uno de los privilegios de las madres parturientas, pues de su elección dependía el futuro del niño, no solo de su salud, sino también de otros valores que se consideraba que podían ser transmitidos por la leche. De ahí que se considerara necesario que el ama fuese una mujer cristiana vieja, buena cristiana, sana y de buen carácter. De esta forma Núñez, en el capítulo 11 de su libro, así como otros autores, se ocuparon detenidamente de las propiedades que debía tener un ama de cría, qué leche era mejor, y, sobre todo, "qué remedios hay para que venga la leche si falta».

En efecto, una de las preocupaciones era que «la leche de la madre o de la ama se multiplique y aumente». Para ello Núñez o Lobera recomendaban el consumo de queso freso y de leche cocida, simiente de zanahoria o hinojo mezclada con caldo de garbanzos, caldo de gallina con polvo de canela y yema de huevo y cardamomo, puche (gachas) de harina de habas o de arroz mezclado con leche y azúcar y agua con miel, acelgas con comino y miel, puerros y berza cocidos, manteca de vaca, etc., además de otros ingredientes ${ }^{114}$.

\section{CONCLUSIONES}

Los textos recogidos revelan algunas cuestiones de interés. La primera, y más evidente, es que la preocupación por la alimentación de la mujer embarazada no es exclusiva de la contemporaneidad, e incluso nos sorprende por la delicadeza y especial atención que estos médicos de la temprana modernidad dirigen a la parturienta.

Es difícil llegar a establecer si los alimentos recomendados en las diferentes fases descritas eran los que realmente se comían, pues reflejan más unas reglas que una práctica real; pero lo que sí hay que destacar es que tales libros nos ayudan a configurar el pensamiento de una época ${ }^{115}$ en este caso, en torno a la salud y cuidado de la mujer embarazada. Es muy probable que, en la mayoría de los casos, las mujeres optaran por razones económicas y culturales, por limitar su alimentación a unos alimentos concretos y disponibles y que tradicionalmente eran considerados aptos para una embarazada o para una mujer en proceso de recuperación tras el parto.

En esta línea, la teoría humoral, aunque estaba presente en la tratadística médica, no tuvo un especial protagonismo en los libros o Artes de cocina de los siglos XV-XVII, y tampoco lo tuvo en los tratados específicos sobre el embarazo y el parto y su relación con la alimentación. Las virtudes de los alimentos, calientes o fríos, húmedos o secos, se recomendaban no tanto por el embarazo sino para atender problemas y enfermedades derivados del mismo. Las recomendaciones para embarazadas y puérperas, eran de otro carácter.

Lo que sí prevaleció, por encima del sistema humoral, fue un conjunto de tradiciones y costumbres sobre la alimentación de la embarazada y de la parturienta, que estuvo por encima tanto de una dietética antigua como de las innovaciones de finales del siglo XVII y su progresiva disociación del ámbito médico. Por otra parte,

114. Núñez, Libro del parto humano, fols. 117v-121r; Lobera de Ávila, Libro del regimiento, fol. $78 \mathrm{r}$. 115. Leschziner, 2006, p. 424. 
tampoco es de extrañar, pues el ámbito de la comida y de la alimentación doméstica pertenecía, casi en exclusiva, a las mujeres: embarazo, parto, puerperio y alimentación eran, por tanto, espacios femeninos que obedecían a una tradición femenina transmitida durante generaciones, avalada (y enriquecida) por los aportes de la tradición médica. De su pervivencia en España, nos dicen mucho los resultados de las encuestas etnográficas, como las del Ateneo de Madrid de 1901, o las realizadas por los grupos Etniker y sintetizadas en el Atlas Etnográfico de Vasconia, en donde esta alimentación (caldos de ave, vino, u otros como canela o azúcar) aparecen con insistencia en todas las fases del embarazo y puerperio, de la misma manera en que estuvieron presentes en el Siglo de Oro.

\section{BiBLIOGRAFÍA}

Adelman, Juliana, y Haushofer, Lisa, «Introduction: Food as Medicine, Medicine as Food», Journal of the History of Medicine and Allied Sciences, 73.2, 2018, pp. 127-134.

Aichinger, Wolfram, «Childbirth Rhythms and Childbirth Ritual in Early Modern Spain, together with Some Comments on the Virtues of Midwives», Hipogrifo. Revista de literatura y cultura del Siglo de Oro, 6.1, 2018, pp. 391-415.

Albala, Ken, Eating Right in the Renaissance, Berkeley, University of California Press, 2002.

Albala, Ken, «Food for Healing: Convalescent Cookery in the Early Modern Era», Studies in History and Philosophy of Biological and Biomedical Sciences, 43, 2012, pp. 323-328.

Alonso y de los Ruices de Fontecha, Juan, Diez previlegios para mujeres preñadas, Alcalá de Henares, Luis Martínez Grande, 1606.

Álvarez Miraval, Blas, Libro intitulado la conservación de la salud del cuerpo y del alma para el buen regimiento de la salud y más larga vida de la alteza del serenísmo príncipe don Filipe, nuestro señor, Medina del Campo, Sanctiago del Canto, 1597.

Anderson, Bonnie S., y Zinsser, Judith P., Historia de las mujeres. Una historia propia, Barcelona, Critica, 2009.

Ateneo de Madrid, Edición crítica de la Información promovida por la Sección de Ciencias Morales y Políticas del Ateneo de Madrid en el campo de las costumbres populares en los tres hechos más característicos de la vida: nacimiento, matrimonio y muerte (1901-1902). Tomo 1. Vol. 2. Nacimiento (Alumbramiento, bautizo, hijos ilegítimos), ed. Antonio Limón Delgado y Eulalia Castellote Herrero, Madrid, Museo del Pueblo Español, 1990. 
Atlas Etnográfico de Vasconia. 9. Ritos del nacimiento al matrimonio en Vasconia, Bilbao, Etniker Euskalerria / Eusko Jaurlaritza / Gobierno de Navarra, 1998.

Aut. = Real Academia Española, Diccionario de autoridades, ed. facsímil, Madrid, Gredos, 1990, 3 vols.

Baernstein, P. Renée, y Christopoulos, John, «Interpreting the Body in Early Modern Italy: Pregnancy, Abortion and Adulthood», Past \& Present, 223, 2014, pp. 41-75.

Barrios, Juan, Verdadera medicina, cirugía y astrología en tres libros dividida, México, Fernando Balli, 1607.

Bovistuau, Pierre, El Teatro del Mundo, Alcalá, Andrés de Angulo, 1564.

Bynum, Caroline Walker, «Fast, Feast, and Flesh: The Religious Significance of Food to Medieval Women», Representations, 11, 1985, pp. 1-25.

Bynum, Caroline Walker, Holy Feast and Holy Fast. The Religious Significance of Food to Medieval Women, Berkeley, University of California Press, 1988.

Cabranes, Diego de, Hábito y armadura espiritual, Mérida, Francisco Díaz Romano, 1544.

Cabrera de Córdoba, Relación de las cosas sucedidas en la corte de España desde 1599 hasta 1614, Madrid, Imprenta de J. Martín Alegría, 1857.

Carbón, Damián, Libro del arte de las comadres o madrinas y del regimiento de las preñadas y paridas y de los niños, Mallorca, Hernando de Cansoles, 1541.

Carlos Varona, María Cruz de, Nacer en palacio. El ritual del nacimiento en la corte de los Austrias, Madrid, Centro de Estudios Cultura Hispánica, 2018.

Dioscórides Anazarbeo, Pedacio, Acerca de la materia medicinal y de los venenos mortíferos, Anvers, Juan Latio, 1555.

Epstein, Julia, «The Pregnant Imagination, Fetal Rigths and Women's Bodies: A Historical Inquiry», Yale Journal of Law \& the Humanities, 7, 1995, pp. 139-162.

Eshleman, Michael Kaye, Diet in Pregnancy in the Sixteenth and Seventeenth Centuries, Yale, Yale Medicine Thesis Digital Library, 1974.

Espejo de la consciencia, Medina del Campo, Alexo de Herrera y Francisco del Canto, 1552.

Evans, Jennifer, «"They are Called Imperfect Men": Male Infertility and Sexual Health in Early Modern England», Social History of Medicine, 29.2, 2014, pp. 311-332.

Fajardo de León, Alonso, Apología por la verdad que tiene la urina como señal de la preñez, Écija, Luis Estupiñán, 1633.

Ferlan, Claudio, «Ayuno eclesiástico», Max Planck Institute for European Legal History. Research paper series, 2018-09, pp. 1-27.

Fuentelapeña, Antonio, Discurso único novísimo que muestra hay en naturaleza animales irracionales invisibles y cuáles sean, Madrid, Imprenta Real, 1676. 
García Herrero, Carmen, «Huevos y gallinas en los inicios de la vida», en Artesanas de vida. Mujeres de la Edad Media, ed. Carmen García Herrero, Zaragoza, Institución Fernando el Católico, 2009, pp. 109-125.

Gentilcore, David, Food and Health in Early Modern Europe. Diet, Medicine and Society, 1450-1800, London, Bloomsbury, 2015.

Gomis Coloma, Juan, «Romances conyugales: buenas y malas esposas en la literatura popular del siglo XVIII», Tiempos Modernos, 6, 18, 2009, pp. 1-26.

González Hernando, Irene, «La figuración de la ciencia. Espacio y objetos de parto en el arte medieval español», Goya, 342, 2013, pp. 3-17.

González Rovira, Javier, «Imaginativa y nacimientos prodigiosos en algunos textos del Barroco», Criticón, 69, 1997, pp. 21-31.

Gordonio, Bernaldo, Lilio de medicina, Toledo, Juan de Villaquirán, 1513.

Gowing, Laura, Common Bodies: Women, Touch, and Power in Seventeenth-Century England, New Haven, Yale University Press, 2003.

Heal, Felicity, «Food Gifts, the Household and the Politics of Exchange in Early Modern England», Past \& Present, 199, 2008, pp. 41-70.

Izquierdo Guerrero, María de las Mercedes, Estudio de los hábitos alimentarios y conocimientos nutricionales en embarazadas de distintas áreas de salud de la Comunidad de Madrid, Madrid, Universidad Complutense de Madrid, 2016.

Keller, Eve, Generating Bodies and Gendered Selves. The Rhetoric of Reproduction in Early Modern England, Seattle, University of Washington Press, 2007.

Kremmel, Nina B., «Pregnancy: Privileges and Protection in the Spanish Golden Age», Hipogrifo. Revista de literatura y cultura del Siglo de Oro, 6.1, 2018, 467-481.

León, Pablo de, Libro llamado guía del cielo, Alcalá de Henares, Juan de Brocar, 1553.

Leschziner, Vanina, «Epistemic Foundations of Cuisine: A Socio-cognitive Study of the Configuration of Cuisine in Historical Perspective», Theory and Society, 35, 2006, pp. 421-443.

Leschziner, Vanina, y Dakin, Andrew, «Hacia una teoría de la cocina desde el Medioevo hasta la Edad Moderna: estructuras cognitivas, biología del gusto y convenciones culinarias», Revista Colombiana de Sociología, 37.1, 2014, pp. 199-218.

Lobera de Ávila, Luis, Libro del regimiento de la salud y de la esterilidad de los hombres y mujeres y de las enfermedades de los niños, Valladolid, Sebastián Martínez, 1551.

López de Corella, Alonso, Secretos de filosofía y astrología y medicina, y de las cuatro matemáticas sciencias, Zaragoza, Pedro Bernuz, 1547. 
López Gutiérrez, Luciano, Portentos y prodigios del Siglo de Oro, Madrid, Nowtilus, 2012.

Maldonado-Durán, Martín, Sauceda García, Juan Manuel, y Lartigue, Teresa, «Cambios fisiológicos y emocionales durante el embarazo normal y la conducta del feto», Perinatología y Reproducción Humana, 22.1, 2008, pp. 5-14.

Mejía, Pedro, Silva de varia leción, Sevilla, Juan Cromberger, 1540.

Nieremberg, Juan Eusebio, Curiosa filosofía y tesoro de maravillas de la naturaleza examinadas en varias cuestiones naturales, Madrid, Imprenta del Reino, 1630.

Núñez, Francisco, Libro intitulado del parto humano, en el cual se contienen remedios muy útiles y usuales para el parto dificultoso de las mujeres, con otros muchos secretos a ello pertenescientes, Alcalá, Juan Gracián, 1580.

Perkins, Wendy, Midwifery and Medicine in Early Modern France. Louise Bourgeois, Exeter, University of Exeter Press, 1996.

Roodenburg, Herman W., «The Maternal Imagination. The Fears of Pregnant Women in Seventeenth-Century Holland», Journal of Social History, 21.4, 1988, pp. $701-716$.

Rublack, Ulinka, «Pregnancy, Childbirth and the Female Body in Early Modern Germany», Past \& Present, 150, 1996, pp. 84-110.

Ruscelli, Girolamo, Secretos del reverendo don Alexo Piamontés, Madrid, Mateo Fernández, 1661.

Sales, Francisco de, Cartas espirituales. Primera parte, ed. Francisco de Cubillas Doniague, Barcelona, a costa de Antonio Ferrer, Miguel Planella, Juan Casañas, Miguel Badía y Pedro Pau, 1686.

Sánchez, Pedro, Triángulo de las tres virtudes teológicas, fe, esperanza y caridad y cuadrángulo de las cuatro cardinales, prudencia, templanza, justicia y fortaleza, Toledo, Tomás de Guzmán, 1595.

Schneider, Eric B., «Inescapable Hunger? Energy Cost Accounting and the Costs of Digestion, Pregnancy, and Lactation», European Review of Economic History, 17.3, 2013, pp. 340-363.

Scott, Susan, y Duncan, Christopher J., «Malnutrition, Pregnancy and Infant Mortality: A Biometric Model», The Journal of Interdisciplinary History, 30.1, 1999, pp. 37-60.

Sevillana medicina. Que trata el modo conservativo y curativo de los que habitan en la muy insigne ciudad de Sevilla, la cual sirve y aprovecha para cualquier otro lugar destos reinos, Sevilla, Andrés de Burgos, 1545.

Sierra, José Martín de la, Mapa de arcanos y verdades de nuestra católica religión, comentando el catecismo del padre Gerónimo de Ripalda, de la Compañía de Jesús. Tomo primero, Madrid, Imprenta de don Gabriel del Barrio, 1718. 
Sorapán de Rieros, Juan, Medicina española contenida en proverbios vulgares de nuestra lengua, vol. 1, s. I., Martín Fernández Zambrano, 1616.

Soriano, Gerónimo, Libro de experimentos médicos fáciles y verdaderos, Alcalá, Juan Gracián, 1612.

Tabernero, Cristina, «Las denominaciones de parir y malparir en la historia del léxico», Historia Autónoma, 16, 2020, pp. 83-100.

Torre y Valcárcel, Juan de la, Espejo de la filosofía y compendio de toda la medicina teórica y práctica, Amberes, Imprenta Plantiniana, 1668.

Toulalan, Sarah, «"To[o] Much Eating Stifles the Child": Fat Bodies and Reproduction in Early Modern England», Historical Research, 87, 235, 2014, pp. 65-93.

Usunáriz, Jesús M., «El padre ante el parto en la España de los siglos XVI y XVII», Hipogrifo. Revista de literatura y cultura del Siglo de Oro, 6.1, 2018, pp. 483-502.

Vaughan, Theresa A., Women, Food, and Diet in the Middle Ages: Balancing the Humours, Ámsterdam, Amsterdam University Press, 2020.

Vega, Diego de la, Paraíso de la gloria de los santos, Lisboa, Pedro Crasbeeck, 1603.

Weiss-Amer, Melitta, «Medieval Women's Guides to Food during Pregnancy: Origins, Texts, and Traditions», Canadian Bulletin of Medical History / Bulletin Canadien d'Histoire de la Médecine, 10.1, 1993, pp. 5-23.

Yepes, Diego de, Discursos de varia historia que tratan de las obras de misericordia y otras materias morales, con ejemplos y sentencias de santos y gravísimos autores, Toledo, Pedro Rodríguez, 1592. 